\title{
1. Nation-building in Australia: a discourse, iconic project or tradition of resonance?
}

\section{John Wanna}

Canada's national cultural museum, the Canadian Museum of Civilisation, located on the Ottawa River in Hull, Quebec, looking back over the capital Ottawa, is a national tribute to the history of Canada - or at least to the way modern Canadians would like their past to be remembered. It is perhaps one of the most 'politically correct' places in the world - with no hint of oppression of First Nation peoples, and nothing but cordial relations between the Anglo and French settlers. The curators can afford to upset no one. It is myth founded on myth. Two main themes stand out in its collections and stunning recreations of the past: the native Indian cultures, especially around the initial decades of white contact; and fabricated stories of European settlement.

The museum includes collections of huge native totem-poles, elaborate and laced with spiritual meaning and reincarnation. It displays Indian carvings, items of Chief Sitting Bull's clothing and west coast war canoes. It presents a simulated forest, settler huts and farms, village centres and seashore settlements. It also chronicles the rapid exploration by the explorers and fur-trappers, Arcadian peasant farmers, the coastal cod fishing and whaling settlements, early French townships, mid-west grain silos astride the rail tracks. It also contains the main national symbols: the Canadian Pacific Railway linking east and west (the 'ribbons of steel'), and the Canadian postal service. These are the contemporary representations of Canadian nation-building across an unforgiving expansive continent.

Australia has no real equivalent. Our National Museum of Australia, on an equally impressive site overlooking Lake Burley Griffin in Canberra, has a far more limited collection and little sense of our nation-building project(s). It carries the occasional iconic implements of traditional Australiana, such as Victa lawn mowers, Hill's hoists for backyard washing, a garish 1950s kitchen, and buffalo-catching jeeps from the Northern Territory outback. But it does not really disentangle a set of nation-building stories or celebrate nationhood. It has a small, anodyne section devoted to Federation in 1901, complete with polystyrene arches and photos of celebrating crowds. The National Museum is more a commemoration of incidentalism than a celebration of nationhood (however understood or from whichever narrative). Its Indigenous collection 
reflects a history of struggle and marginalisation — including biographies of individuals of the 'stolen generation'.

But, what do these recent representations tell us - encapsulated as they are in their respective cultural institutions? Both the Canadian and Australian institutions are keen to propound their own views of their nation's pasts. Both offer a sanitised reconstruction of the past - with historical resonances viewed through the lens of modern sensibilities. Canada celebrates the contributions of its various peoples but with the deep-seated conflicts airbrushed out of the picture; Australia assembles items that shaped the Australian consciousness, iconic but inherently random. Canada uses poetic licence to heighten dramatic effect; Australia uses pragmatism and practical inventions to record our occupancy of the continent.

Yet, these are both settler societies that formed federal nations as an answer to geographic scale and regional differences. They both have 'long' histories (of ancient peoples) and 'recent' histories (of settler colonisation). If colonisation is problematic and difficult to recount or take any discernable pride in, popular symbols of nation identity are a much more safe topic attracting less controversy. But how do nations capture and construct their past. What do they include and exclude? How they capture their past is itself an important 'nation-building' narrative and gives indications about the national psyche looking both forwards and backwards.

From the early days of white settlement, the Australian polity has had to contend with adversity. Governments had to deal with a large dry continent, vast distances, a harsh climate, and a scattered but mobile population. Everything appeared to be in short supply. After the 'British Invasion' the notion of an empty continent (as opposed to terra nullius) took on two different meanings: the Indigenous people had a very low population density and were expected to be bred out or die out; and nothing was built or developed for the colonialists to use or rely upon.

Each state had its own various narratives about conquering and coping with the Australian emptiness. For some there was a belief in the notion that rain followed the plough, that the drive to settle marginal lands would temper the climate. Others believed that intrepid explorers would discover inland seas and rivers turning back to water the centre. Others felt that the gold rushes would provide the opportunistic means to develop secluded regions and relocate populations. Railways in the nineteenth century proved one of the more enduring forms of opening up the countryside and connecting the coastal capitals to emergent provincial towns and to the productive hinterlands. Every bush town and prospective hamlet wanted a rail artery. Occasionally, optimism triumphed over reality. Entire cities could be laid out in selected inland sites by planners and 
administrators anxious to populate the bush. Their follies would be pardoned by the fixation to build the nation.

Over time, Australia arguably developed a fascination with nation-building in an empty continent. It had to build from scratch. And the 'building' was literal. It consisted of connecting places by roads, by rail, and by sea through ports and jetties. It meant building palatial central railway stations and networks of regional stations, ornate classical parliament houses in each colony (the cost of which nearly drove some of the early colonies bankrupt). It meant building government administrative precincts and constructing local housing projects often with innovative statutory authority organisations and specialist government commissions. It was an engineer's state, often resourced by borrowed funds from UK banks.

But, how do we understand the nation-building discourse today? I suggest there are four possible interpretations we can derive from its usage.

First, nation-building is a 'new world' phenomenon and discourse. It resides in the huge landmasses of the Americas, Africa and Australasia. There is little equivalent discourse in the old world of Europe, China or Japan, although Communist Russia developed its own variety in its strenuous efforts to 'catch up with the west' from the 1920s onwards. In the 'new world' societies this discourse implies the taming of enormous wildernesses by colonialist regimes, usually through the provision of fundamental infrastructure. It extols the pioneering spirit - either collectively as in the case of Australia and occasionally Canada, or individually in the case of the United States. Baudrillard and Benedict Anderson often tried to capture the retrospective images of this discursive culture and its signifiers.

Second, nation-building can be used in connection with particular policy proposals. These become icon policies or icon projects. Such projects are treated differently than the norm. They are devised and formulated in non-standard ways, exceptions are made, and arguments in their favour are able to cut through. Iconic propositions seem able to gain institutional and popular support and projects emerge from the drawing board to construction. Iconic policies draw on popular emotions and rely on sentiment to get them through the normal policy process. Iconic policies that 'work' are lauded for their prescience and forward-thinking capabilities; iconic policies that 'fail' are ridiculed as white elephants with those involved left fighting the war of excuses. But, interestingly, the fact that white elephants repeatedly occur at regular intervals does not seem to shake the implacable faith of those interested in promulgating the next wave of nation-building projects. The iconic dreamers and fabricators appear immune to the risks or warnings of failure. They cut through.

Thirdly, nation-building can be regarded as a governance tradition that has great resonance at certain times. Such a tradition is something that waxes and 
wanes in and out of favour but holds a deep resonance in people's consciousness. Politicians and administrators feel a deep need to periodically do something 'to add to the building of the nation'. It is a set of beliefs within governance in the same way that Westminster, ministerial responsibility, or public service independence are resonance traditions. They are not always there and consciously prominent but are turned to periodically, to assist in periods of stress or turbulence. Resonance traditions suggest that there is the need every now and again to have a demonstration effect - returning to customary traditions of nation-building to help renegotiate our politics with the present.

Fourthly, the usage of the term is generally skewed towards the harder infrastructural meanings, but it does not have to be so. Nation-building carries a certain 'boys toy' ring. It means monuments, earthworks, big dams, suspension bridges, hydo-electric schemes. It does not usually mean, for instance, taxation collection - which is fundamentally a means of collective saving and investing in society both now and into the future. Indeed, taxation is usually considered as simply a drain on economic potential for some limited collective public goods. We tend to understand 'taxation' and compulsory saving from a liberal individualist position (on the assumption that people know how to spend their personal wealth better than the community does) rather than from a nation-building perspective - and yet taxation may have played a far greater role in Australia's nation-building than any iconic project or monument. Similarly, annual budgets of government can be seen as nation-building statements - but they are more conventionally regarded as simply recurrent spending plans. Taking this point a step further, the term nation-building is not much used to describe the routine administration of state so essential to good governance (although elements of this do appear in Michael Pusey's classic sociological study of the post-war administrative elite who were changing their minds from being nation-builders to economic rationalists). It is not used to describe the operation of the health or education system so essential to our productive life and standard of living. These 'invisible' forms of nation-building are subterranean but foundational. They are the 'excluded voices' from the discourse but which we need to acknowledge in a more complete assessment of the nation-building exercise.

In the chapters that follow we canvass these various interpretations at greater length, while in particular exploring the various strictures or obsessions that have characterised our nation-building experiences. We ask questions about the Australian discourse over time - what has happened and what is happening to the discourse, is it alive and well, going underground, undergoing transformation or in need of renewal and re-imagining.

The chapters by John Butcher, Michael Pusey, Anna Clark and Ian Marsh all explore the dimensions of the changing discourse — providing their own 
assessments and suggestions for reinvention. Other authors are more interested in how ideologies and professional strictures have shaped or channelled nation-building into certain paths. So, Fred Argy discusses how economic doctrines accepted by the Australian state have produced a 'fiscal straitjacket' that has held back economic development. Anthony Shepherd discusses why the state lost interest in nation-building agendas, and what might rekindle greater interest today. Michael de Percy asks whether conformism, standardisation and central controls serve the interests of nation-building in policy sectors that rely more on vibrancy and collaborative innovation. He compares Australia's slow progress with the new icon of fast broadbanding to Canada's more entrepreneurial, community-based but also effective approach to policy development.

Others bring the discussion back to the unconventional dreaming and periodic subscription to bizarre projects that have existed over time and still retain some attraction to modern policy-makers (semblances of traditions of resonance). Robert Wooding wonders why so many otherwise sensible people have continued to dream of massive inland waterworks as a way of filling the empty continent. The dream of castles in the air still finds its adherents especially when tough times such as extended droughts hit the continent. Richard Evans reminds us of our penchant for the white elephant - where conceptualisation was often more important than the social outcomes achieved. Lyndsay Neilson recounts how the Building Better Cities urban infrastructure program of the Hawke and Keating era was put together (a white elephant in some quarters but a planning renaissance in others). He looks at the legacy of such an ambitious program over a decade after it was aborted by the Howard government.

This monograph reminds the contemporary policy debate about the resonances of nation-building. It stresses the importance of the tradition in historical context but also probes its limitations and shortcomings. Together these essays suggest the need for reinvention and recasting in our beliefs about nation-building as we negotiate a more complex policy future. 